\title{
Extraction of Gelatin from Different Parts of Gallus Gallus Domesticus
}

\author{
H. Ab Rahim ${ }^{1,2}$, H. Ahmad² and M.H. Ab Rahim³ \\ ${ }^{1}$ Food Technology Department, Politeknik Sultan Haji Ahmad Shah, Semambu \\ 25350, Kuantan, Pahang, Malaysia \\ ${ }^{2}$ Centre for Modern Languages and Human Sciences, Universiti Malaysia Pahang, Lebuhraya Tun Razak, 26300 Gambang, \\ Kuantan, Pahang, Malaysia \\ ${ }^{3}$ Faculty of Industrial Sciences \& Technology, Universiti Malaysia Pahang, Lebuhraya Tun Razak, 26300 Gambang, Kuantan, Pahang, Malaysia
}

\begin{abstract}
Gelatin is a mixture of protein obtained from animal parts (skin, bones, tendons, ligaments, and cartilages) by hydrolysis. Gelatin market demand is high especially in pharmaceutical, food, photographic, and cosmetics industries based on its gelling, foaming, and emulsifying properties. This preliminary study was focus on chicken head and feet gelatin extraction and their characterization in terms of percentage yield and physical properties $(\mathrm{pH}, \mathrm{color}$, melting point, and texture). Two different treatments (acid and alkali) were used. The percentage yield of chicken head (CHGac) and feet (CFGac) gelatins by using acid treatment were $32.10 \%$ and $33.65 \%$ while the chicken head (CHGal) and feet (CFGal) from alkali treatment were $20.06 \%$ and $22.18 \%$ respectively. All the gelatins indicated the same $\mathrm{pH}$ pattern range from 4.3 to 6.4 . The melting point for gelatins from each treatment was a range from $30.4^{\circ} \mathrm{C}$ to $35.9^{\circ} \mathrm{C}$. The texture analysis is specifically into the gel strength of gelatin produce which ranges from $230 \mathrm{~g}$ to $356 \mathrm{~g}$. All the gelatins also showed the same pattern of $d$ (lighter/darker), da(redder/greener), and $\mathrm{db}$ (yellower/bluer) which are positive value mean that the gelatins have lighter, redder and yellower color respectively. In conclusion, chicken head and feet can be an alternative that could replace the usage of porcine, bovine, and other mammals as a source of gelatin.
\end{abstract}

ARTICLE HISTORY

Received: $26^{\text {th }}$ Aug 2020

Revised: $12^{\text {th }}$ Jan 2021

Accepted: $30^{\text {th }}$ Mac 2021

\section{KEYWORDS}

Gallus gallus domesticus

Chicken feet

Chicken head

waste

Poultry industry

\section{INTRODUCTION}

The poultry industry in Malaysia is one of the highest demand food sectors with an estimated consumption in 2020 is up to $49.3 \mathrm{~kg}$ of poultry meat per capita. As an essential protein source in Malaysia with an average annual production (2013-2019) of 1638 million tons of chicken meat, it is denoted that, $0.82 \%$ of enhancement in production of broilers in 2019 [1]. The rapid development of this industry has led to an abundance of by-products produced during the slaughtering processes. Consequently, these by-products will result in environmental problems such as soil pollution, air pollution, pathogens, heavy metals, and water quality problems [2] [3]. However, if these abundant by-products are fully utilized with an innovative idea with the aid of technology, it will certainly contribute to economic growth and give the valueadded to the entire poultry industry chain without affecting the environment. By implementing the Sustainable Development Goals (SDGs), the socioeconomic and sustainability environment could be achieved by utilizing the byproducts from the poultry industry (head and feet) to generate value-added products applicable to pharmaceutical, cosmetics, food, and tissue engineering industries [4] [5]. The chicken head that is commonly used in animal feed is rich in collagen mainly in a comb, wattle, skin, bones, and cartilages able to produce high bloom strength of Type-A gelatin that higher than bovine gelatin [6]. The same goes for chicken feet, this waste product received special attention due to nutritional content that gives benefits to human health and value-added to food, cosmetics, and pharmaceutical industries because of its capability to form a gel, bind, and act as an emulsifier. Both types of gelatin (A and B) have different physicochemical properties that lead to different applications [7]. Since the chicken head is a homogenous tissue combination of skin and bone, therefore, the acid and alkali pre-treatment method is applied and basic physical characteristics ( $\mathrm{pH}$, melting point, color, viscosity, bloom strength) of different parts of Gallus gallus domesticus (head and feet) were compared with the commercial bovine gelatin (CBG).

\section{MATERIALS AND METHODS}

Gallus gallus domesticus preparation. Fresh chicken head $(\mathrm{CH})$ and feet $(\mathrm{CF})$ were obtained from Yasin \& $\mathrm{Al}-\mathrm{Haj}$ Enterprise at Beserah Kuantan, Malaysia. Once received, all parts were cleaned and weighed for $5 \mathrm{~kg}$ each using Shimadzu digital balance and recorded. Then, the cleaned samples were ground using a Philips food processor (HR77629). The ground samples were vacuum packed and stored in a freezer at $-20^{\circ} \mathrm{C}$ before being analyzed.

Defatted process. The defatting process of chicken head $(\mathrm{CH})$ and feet $(\mathrm{CF})$ were conducted using a cold extraction technique [8]. In this process, ethanol $(\mathrm{C} 2 \mathrm{H} 5 \mathrm{OH})$ and petroleum ether $(\mathrm{C} 6 \mathrm{H} 14)$ were mixed with a ratio of $1: 1$. Then the ground chicken head and feet were homogenized for $6 \mathrm{~h}$ with the 1:1 ethanol-pet ether according to 1:6 (w/v) ratios. The 
homogenized solution was collected using Edwards vacuum filter, UK, and transferred into the desiccator till the filtrate dry.

\section{Gelatin pre-treatment and extraction}

Acid-soluble extraction. The defatted chicken feet $(\mathrm{CF})$ and head $(\mathrm{CH})$ were soaked, shaken, stirred, and stored at room temperature in 5\% (v/v) lactic acid $(\mathrm{C} 3 \mathrm{H} 6 \mathrm{O} 3)$ solution for three days where this pre-treatment method was adapted and modified from [9]. The chicken feet and head were properly and completely immersed in the lactic acid (C3H6O3) solution to remove the non-collagenous material. After three days, the lactic acid (C3H6O3) solution was removed and drained from the chicken feet and head followed by a neutralization process by adding $0.2 \mathrm{M}(1: 4 \mathrm{w} / \mathrm{v})$ sodium hydroxide $(\mathrm{NaOH})$ until a $\mathrm{pH}$ of 7 was reached. The mixture of the samples was centrifuged for 60 min before undergoing hot water extraction at $85^{\circ} \mathrm{C}$ for $1 \mathrm{~h}$ before filtered by using vacuum filtration. The extracted gelatin was freeze-dried by laboratory freeze dryer Crist, the UK then kept for analysis.

Alkali-soluble extraction. $100 \mathrm{ml}$ of distilled water was added into defatted chicken feet (CF) and head $(\mathrm{CH})$ and centrifuged for $20 \mathrm{~min}$. Then, $0.15 \%$ of sodium hydroxide $(\mathrm{NaOH})$ was added into a defatted solution by centrifuging for $40 \mathrm{~min}$ and repeated for 3 cycles. $0.7 \%$ citric acid was then added to the supernatant and continues for centrifugation for $10 \mathrm{~min}$. This method was carried out for 3 cycles by referring to [10] with several modifications. The supernatant was added with $100 \mathrm{ml}$ of distilled and continue to centrifuge for $10 \mathrm{~min}$ and let it cool for $15 \mathrm{~min}$. After cooling, $4 \mathrm{~g}$ of activated carbon was mixed and filtered after $20 \mathrm{~min}$ using vacuum filtration. The filtered supernatants were undergoing hot water extraction at $85^{\circ} \mathrm{C}$ for $1 \mathrm{~h}$ and the concentrated chicken head gelatin (CHG) and chicken feet gelatin (CFG) solutions were dried in a laboratory freeze dryer Crist, the UK.

Figure 1 simplifies the treatment process using different methods and parts of Gallus gallus domesticus.

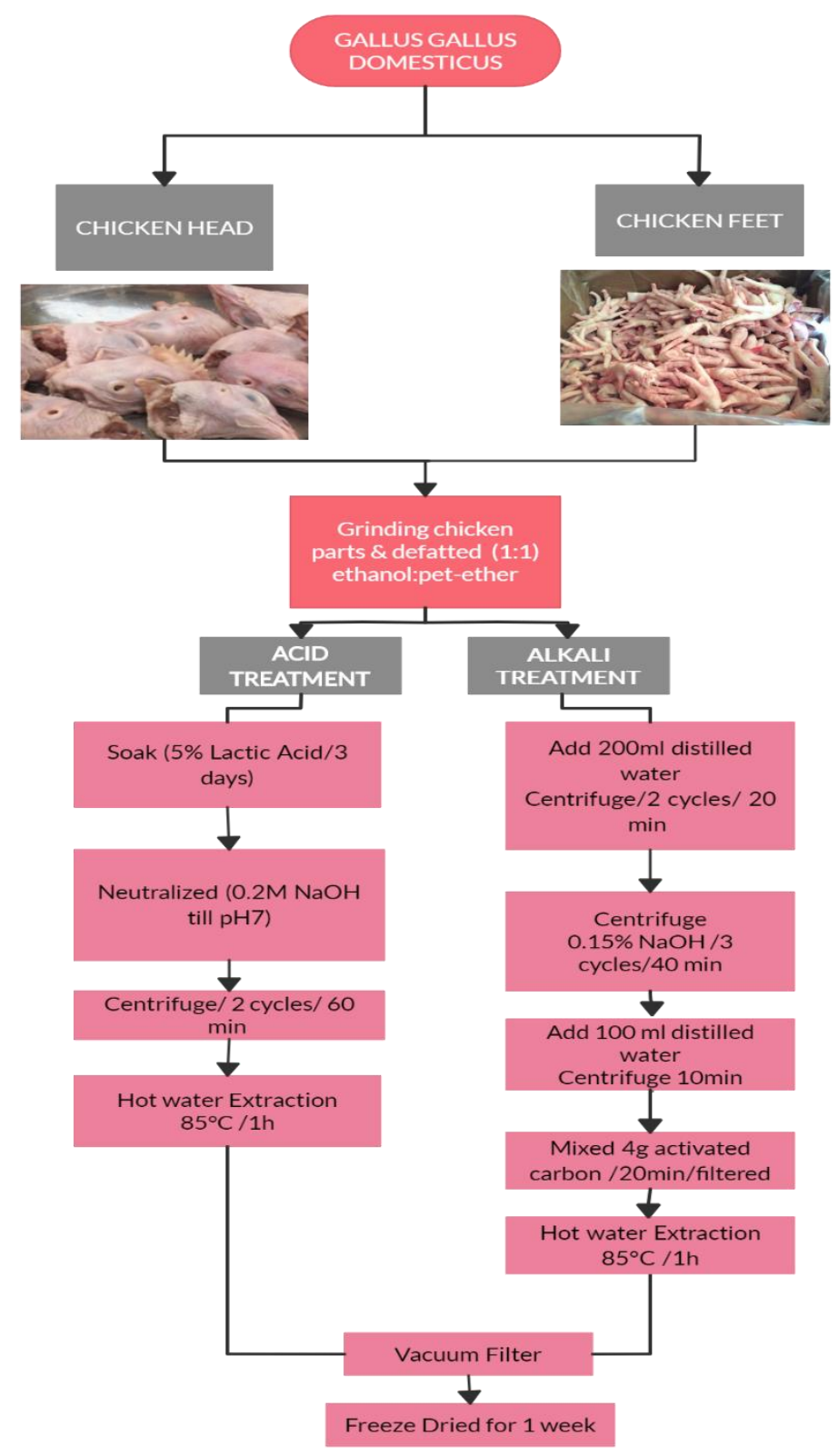

Figure 1 Treatment process using different methods and parts of Gallus gallus domesticus 


\section{Physical Analysis}

Percentage yield determination. The percentage yield of gelatin was conducted by referring to [11]. The extraction yields of the gelatin were calculated based on the dry basis equation.

$$
\text { Yield }(\%)=\frac{\text { Dry weight of gelatine }(\mathrm{g})}{\text { Dry weight of chicken parts }(\mathrm{g})} \times 100 \%
$$

Gel strength measurement. Gel strength analysis was conducted by referring to [11]. The bloom strength was measured by using Brookfield CT3 Analyzer, the USA with a $12.7 \mathrm{~mm}$ cylindrical plane surface and a sharp edge probe (AAC standard for bloom test). The speed was set up at $1 \mathrm{~mm} / \mathrm{s}$ with a $5 \mathrm{~mm}$ targeted distance.

Color measurement. The $\mathrm{CHG}$ and $\mathrm{CFG}$ were measured using a calibrated Hunter Lab Color Quest XE spectrophotometer. The symbols $\mathrm{L}^{*}, \mathrm{a}^{*}$ and $\mathrm{b}^{*}$ indicated dl(lighter/darker), da(redder/greener), and db(yellower/bluer) of samples, respectively.

pH measurement. The $\mathrm{pH}$ value for $\mathrm{CHG}$ and CFG solution was measured with Milwaukee MW102 PRO, the USA based on [11]. $7.14 \%(\mathrm{w} / \mathrm{v})$ of the gelatin solution was placed in a water bath for $15 \mathrm{~min}$ at $65^{\circ} \mathrm{C}$. Two-point calibration was performed in buffer solutions at $\mathrm{pH} 4$ and $\mathrm{pH} 7$.

Melting point measurement. The glass capillary tube was prepared for melting point gelatins determination. The capillary tube was inserted into the melting point apparatus. The temperature was set at $25^{\circ} \mathrm{C}$ and the heating rate was programmed where the temperature will increase $1^{\circ} \mathrm{C}$ for every 30 seconds. The melting point was observed through a viewfinder and recorded once the $\mathrm{CHG}$ and $\mathrm{CFG}$ powder melted.

Viscosity measurement. $10 \%(\mathrm{w} / \mathrm{v})$ of the gelatin solution was heated at $60^{\circ} \mathrm{C}$ before measuring the viscosity for CHG and CFG solution with Brookfield Laboratory Viscometer base on [12] by using No. 1 spindle and rotated at 60 rpm.

Statistical analysis. SPSS Statistics Version 17.0 was used [11] to determine the significant difference with mean values of $\mathrm{p}<0.05$ for different parts and methods of gelatin.

\section{RESULTS AND DISCUSSION}

Chicken Head Gelatin (CHG) and Chicken Feet Gelatin (CFG) percentage yield. Gelatin percentage yield from both methods: Chicken Head Gelatin (CHG) and Chicken Feet Gelatin (CFG) represented by a mass of dry weight gelatin per total mass of the chicken part. From Table 1, the percentage yield of CHG and CFG with acid-soluble extraction was slightly higher compared to the alkali-soluble extraction method. The highest percentage yield was obtained from CFGac acid-soluble extraction (33.65\%) may due to longer pre-treatment time compare to alkali-soluble extraction. The extraction yield not only depended on the types of chemicals used but they are also depended on types of raw materials, animal age, collagen content, chemical concentration, time of treatments and extraction, extraction temperature, and method of extraction [13] and [14]. The extracted gelatin for CHG and CFG in both extraction methods were in the range of $20.06 \%$ to $33.65 \%$ based on the dry weight.

Table 1 Characteristics of different methods and parts of Gallus gallus domesticus extracted gelatins

\begin{tabular}{|c|c|c|c|c|c|}
\hline \multirow{2}{*}{ Characteristics } & \multicolumn{2}{|c|}{ Acid-soluble extraction } & \multicolumn{2}{|c|}{ Alkali-soluble extraction } & \multirow{2}{*}{$\begin{array}{c}\text { Commercial } \\
\text { Bovine Gelatin } \\
(\mathrm{CBG})\end{array}$} \\
\hline & $\mathrm{CHG}^{\mathrm{ac}}$ & $\mathrm{CFG}^{\mathrm{ac}}$ & $\mathrm{CHG}^{\mathrm{al}}$ & $\mathrm{CFG}^{\mathrm{al}}$ & \\
\hline Percentage yield (\%) & $32.10 \pm 0.45^{b}$ & $33.65 \pm 1.30^{b}$ & $20.06 \pm 0.36^{\mathrm{a}}$ & $22.18 \pm 1.08^{\mathrm{a}}$ & - \\
\hline Bloom Strength (g) & $320.00 \pm 0.10^{\mathrm{b}}$ & $356.00 \pm 1.00^{\mathrm{b}}$ & $230.12 \pm 0.30^{\mathrm{a}}$ & $268.00 \pm 1.10^{\mathrm{a}}$ & $152 \pm 0.60^{c}$ \\
\hline Viscosity $(\mathrm{cP})$ & $4.49 \pm 0.15^{\mathrm{a}}$ & $4.38 \pm 0.67^{\mathrm{a}}$ & $3.52 \pm 0.22^{\mathrm{b}}$ & $3.35 \pm 0.13^{\mathrm{b}}$ & $4.10 \pm 0.18^{c}$ \\
\hline Melting Point $\left({ }^{\circ} \mathrm{C}\right)$ & $32.3 \pm 0.70^{\mathrm{a}}$ & $35.9 \pm 1.10^{\mathrm{a}}$ & $30.4 \pm 0.05^{b}$ & $31.6 \pm 1.08^{a}$ & $34.5 \pm 0.20^{\mathrm{a}}$ \\
\hline $\mathrm{pH}$ & $4.3 \pm 0.10^{\mathrm{a}}$ & $4.8 \pm 0.04^{\mathrm{a}}$ & $6.2 \pm 0.06^{\mathrm{b}}$ & $6.4 \pm 1.00^{\mathrm{b}}$ & $5.3 \pm 1.20^{\mathrm{c}}$ \\
\hline 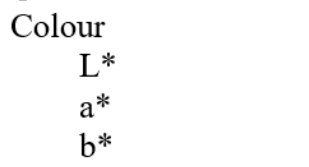 & $\begin{array}{c}62.12 \pm 0.03^{\mathrm{a}} \\
1.73 \pm 0.22^{\mathrm{a}} \\
15.35 \pm 1.90^{\mathrm{a}}\end{array}$ & $\begin{array}{c}53.22 \pm 0.45^{\mathrm{b}} \\
0.17 \pm 0.20^{\mathrm{b}} \\
17.93 \pm 0.08^{\mathrm{b}}\end{array}$ & $\begin{array}{c}55.11 \pm 0.12^{\mathrm{b}} \\
2.01 \pm 0.80^{\mathrm{c}} \\
16.90 \pm 0.56^{\mathrm{c}}\end{array}$ & $\begin{array}{c}59.29 \pm 0.19^{\mathrm{b}} \\
2.74 \pm 0.10^{\mathrm{c}} \\
17.13 \pm 0.65^{\mathrm{b}}\end{array}$ & $\begin{array}{c}52.29 \pm 0.13^{\mathrm{b}} \\
1.27 \pm 0.62^{\mathrm{a}} \\
16.11 \pm 0.42^{\mathrm{c}}\end{array}$ \\
\hline
\end{tabular}

$\mathrm{CHG}^{\text {ac: }}$ Chicken Head Gelatin with acid-soluble extraction method, $\mathrm{CFG}^{\text {ac: }}$ Chicken Feet Gelatin with acid-soluble extraction method, $\mathrm{CHG}^{\text {al: }}$ Chicken Head Gelatin with alkali-soluble extraction method, $\mathrm{CFG}^{\text {al }}$ : Chicken Feet Gelatin with alkali-soluble extraction method. This table represents mean \pm standard deviation values. ${ }_{\mathrm{m}}^{\mathrm{a}-\mathrm{c}}$ in the same row designate significant difference $(\mathrm{P}>0.05) \mid$

From analytical data, it shows that the acid and alkali pre-treatment with different chicken parts gave significantly different ( $p>0.05$ ) on the percentage yield of Gallus gallus domesticus. The previous study from [15],[16], and [17] were using acid and alkali pre-treatment extraction process shows the percentage yield for chicken feet gelatins were in the range of $10.29 \%$ to $30.04 \%$ while for chicken head gelatins by [18] and [19] were $16 \%$ and $31.21 \%$ which were slightly 
lower than this finding. From the result in table 1, it can be observed that the defatted and improvement of pre-treatment extraction techniques for CHG and CFG aids in the percentage yields for both methods, and the alkali-soluble extraction method can be improvised in terms of the pre-treatment cycle to complete the gelatin hydrolysis thus gain the higher percentage yield of gelatin.

Gel strength. Gel strength that is measured with the Bloom test ranges from high $(300 \mathrm{~g})$ to low (50g) represent the quality of gel [20]. Different product applications will require certain Bloom of gelatin. In this study, the commercial bovine gelatin (CBG) had the lowest gel strength (152g) compare to CHGac (320g), CFGac(356g), CHGal(230g), CFGal(268g). The gel strengths in CHGac, CFGac were significantly different ( $<$ 0.05) compare to CHGal, CFGal. Lower gel strength in CHGal, CFGal might due to shorter extraction time which resulted in incomplete hydrolysis of gelatin. This partial hydrolysis results in weakened peptide bone and fewer the $\alpha$-chains consequently, unable to form a stronger molecular bond. Vice versa, high gel strength in CHGac, CFGac were comparable to chicken skin gelatin reported by [21] and higher than gel strength in porcine [22]. A previous study by [19] shows, lower Bloom of chicken head gelatins from $200.4 \mathrm{~g}$ to $247.9 \mathrm{~g}$ were obtained and the gel strength from aforementioned [14], [16], and [21] work were comparable to $\mathrm{CHGal}$, CFGal but lower than $\mathrm{CHGac}$, CFGac. Overall, the $\mathrm{CBG}$ and all the extracted gelatins were applied to food industries as the gel strengths were in the range of medium to high Bloom.

Colour. Table 1 indicated the color of CHG and CFG under different pretreatment methods which represented as $\mathrm{L}^{*}$ (lighter/darker), $\mathrm{a}^{*}$ (redder/greener), and $\mathrm{b}^{*}$ (yellower/bluer). The color attributes for CHG and CFG have significant differences $(\mathrm{p}<0.05)$ when subjected to different extraction methods. The raw material and treatment method resulted in color difference and consumer acceptance [23]. The values of $\mathrm{L}^{*}$ and $\mathrm{b}^{*}$ of CFGal and CBG were lower compare with CFGac, CHGac, and CHGal. The lower L* values were probably due to the longer pre-treatment time as mention by [24]. According to [25], a longer pre-treatment time will result in non-enzymatic browning leading to a decrease of $\mathrm{L}^{*}$ values. For $\mathrm{a}^{*}$ value, only CFGac was greener than redder and there was a significant difference in $\mathrm{b}^{*}$ value for the CHGac towards other extracted gelatin where all of them were more to yellower in color. In brief, the CFGac, CHGac, and CHGal were lighter in color (higher L* value) was preferable than the CFGac alkali-soluble treatment as supported by [26].

$\boldsymbol{p H}$. The types of chemicals and concentrations being subjected to the raw materials will influence the gelatin pH [27]. The range value for $\mathrm{pH} 3.8$ to 5.0 was for type-A gelatins that undergo acid pre-treatment while for type-B gelatin that is subjected to alkali pre-treatment, the range value was $\mathrm{pH} 4.7-7.5$ [28]. From table 1, the $\mathrm{pH}$ of CHGac and CFGac that undergo acid-soluble treatment were 4.3 and 4.8 respectively, while pHs for alkali-soluble treatment (CHGal and CFGal) were 6.2 and 6.4 respectively. The $\mathrm{pH}$ values for $\mathrm{CHGal}$ and $\mathrm{CFGal}$ were close to neutral due to the alkali pre-treatment in the extraction process and the addition of distilled water in each cycle with subjected to carbon filtration before undergoing hot water extraction. The difference in $\mathrm{pH}$ between $\mathrm{CBG}$ and $\mathrm{CHGac}$, CFGac, CHGal, CFGal was found to be not significant $(\mathrm{P}<0.05)$. From the result, it can be concluded that $\mathrm{CHGac}$ and $\mathrm{CFGac}$ were type-A gelatin and $\mathrm{CHGal}$ and CFGal were type-B gelatin with high Bloom strength. Concisely, the $\mathrm{pH}$ range influence by the concentration of the chemical used before pre-treatment and extraction. The pre-treatment step is one of the major factors that influence the pH gelatins.

Melting Point. The melting temperatures for $\mathrm{CHGal}$ and $\mathrm{CFGal}\left(30.4^{\circ} \mathrm{C}\right.$ and $\left.31.6^{\circ} \mathrm{C}\right)$ were lower than $\mathrm{CHGac}$ and $\mathrm{CFGac}\left(32.3^{\circ} \mathrm{C}\right.$ and $\left.35.9^{\circ} \mathrm{C}\right)$. However, no significant differences $(\mathrm{p}<0.05)$ were found between the melting point of $\mathrm{CBG}$ and $\mathrm{CHGac}, \mathrm{CFGac}, \mathrm{CHGal}$, CFGal. The melting point is measured once the gel started to melt which results in decreasing in carbon tetrachloride [29] and this process is connected with Bloom strength and viscosity of gelatin [29]. [29] and [30] mentioned that the melting point of gelatin is influenced by proline and hydroxyproline content. These amino acids assist the collagen stability where hydroxyproline and proline content is proportional to the melting temperature. Therefore, further research can be conducted to determine the hydroxyproline content in $\mathrm{CHGac}, \mathrm{CFGac}$, CHGal, CFGal.

Viscosity. Viscosity is conducted to determine the gelatin quality [31]. From the results, the viscosities of CHGac and CFGac extracted from acid pre-treatment were 4.49 and $4.38 \mathrm{cP}$, whereas the $\mathrm{CHGal}$ and CFGal that extracted from alkali pre-treatment were 3.52 and $3.35 \mathrm{cP}$. Generally, $\mathrm{pH}$, the molecular weight of protein constituents with their distribution will result in differences in gelatins viscosities [32][33]. However, no significant differences $(p<0.05)$ were found between $\mathrm{CBG}$ and $\mathrm{CHGac}, \mathrm{CFGac}, \mathrm{CHGal}, \mathrm{CFGal}$ indicated that these gelatins were applicable for commercialization even though most commercial gelatins viscosities could attain higher than $4.0 \mathrm{cP}$ and may up to $13.0 \mathrm{cP}$ [34]. Due to the high temperature $\left(85^{\circ} \mathrm{C}\right)$ during gelatin extraction, the energy was absorbed by water molecules which result in a declination of $\mathrm{CHGac}, \mathrm{CFGac}$, CHGal, and CFGal viscosities. Based on [35], temperature and time extraction were inversely proportional to viscosity. Therefore, the higher and longer the extraction temperature and time of gelatin, the lower value of viscosity obtained which results in low quality of gelatin produced.

\section{CONCLUSION}

From this preliminary research, basic physical characteristics ( $\mathrm{pH}$, melting point, color, viscosity, bloom strength) of different parts of Gallus gallus domesticus $\mathrm{CHGac}$, CFGac, $\mathrm{CHGal}$, and CFGal were determined and effectively extracted. Different pre-treatment methods define the types of extracted gelatin as CHGac and CFGac indicated Type-A gelatin otherwise $\mathrm{CHGal}$ and $\mathrm{CFGal}$ showed Type-B gelatin which was comparable to the commercial bovine gelatin ( $\mathrm{pH}$, color, melting point, and viscosity) and higher in gel strength (230-320) g. In brief, further physicochemical analysis was highly 
recommended to $\mathrm{CHGac}, \mathrm{CFGac}, \mathrm{CHGal}$, and $\mathrm{CFGal}$ as they have a huge potential to replace porcine, bovine, and other mammals' gelatin in various industrial applications.

\section{ACKNOWLEDGEMENT}

This preliminary research was supported by the Department of Food Technology, Sultan Haji Ahmad Shah Polytechnic, and financially supported by Universiti Malaysia Pahang (UMP) for Research Grant PGRS200329.

\section{REFERENCES}

[1] Information on http://www.dvs.gov.my/ststistik.

[2] I. Bochkareva and E. Maymanova, "Poultry Farms As a Source of Environmental Pollution," Interexpo GEOSiberia, 4 (2019) 106-111.

[3] J. Yang et al., "Evaluation of livestock pollution and its effects on a water source protection area in China," Environ. Sci. Pollut. Res., 27 (2020) 18632-18639.

[4] Information on https://sustainabledevelopment.un.org/.

[5] F. Toldrá, M. Aristoy, L. Mora, and M. Reig, "Innovations in value-addition of edible meat by-products," MESC, 92 (2012) 290-296.

[6] Â. A. Rivera, J. G. Sebranek, R. E. Rust, and L. B. Tabatabai, "Composition and protein fractions of different meat by-products used for pet food compared with mechanically separated chicken ( MSC )," 55 (2000).

[7] R. Huang, J. Zeng, D. Zhao, K. V. Cook, K. D. Hambright, and Z. Yu, "Sediment microbiomes associated with the rhizosphere of emergent macrophytes in a shallow, subtropical lake," Limnol. Oceanogr., 65 (2020) 38-48.

[8] P. Mokrejs, R. Gal, D. Janaeova, M. Plakova, and M. Zacharova, "Chicken paws by-products as an alternative source of proteins," Orient. J. Chem., 33 (2017) 2209-2216.

[9] K. de la C. A. Etxabide, J. Uranga, P. Guerrero, "Gelatin Production from Skin of Chicken Leg using A Variety of NaOH Concentration," J. Ilmu dan Teknol. Has. Ternak, 13 (2018)126-132.

[10] S. Saenmuang, S. Phothiset, and C. Chumnanka, "Extraction and characterization of gelatin from black-bone chicken by-products," Food Sci. Biotechnol., 29 (2020) 469-478.

[11] GMIA, "GMIA, Gelatin Handbook," Gelatin Manuf. Inst. Am., (2019).

[12] T. K. Kim, H. W. Kim, Y. Y. Lee, H. W. Jang, Y. B. Kim, and Y. S. Choi, "Quality characteristics of duck jerky: combined effects of collagen and konjac," Poult. Sci., 99 (2020) 629-636.

[13] P. Songchotikunpan, J. Tattiyakul, and P. Supaphol, "Extraction and electrospinning of gelatin from fish skin," 42 (2008), 247-255.

[14] P. F. Almeida and S. C. D. S. Lannes, "Extraction and physicochemical characterization of gelatin from chicken by-product," J. Food Process Eng., 36 (2013) 824-833.

[15] S. C. Ee, N. Saari, F. Abas, A. Ismail, M. K. Abu Bakar, and J. Bakar, "Properties of chicken head gelatins as affected by extraction method," Int. Food Res. J., 26 (2019) 499-508.

[16] R. Widyasari and S. Rawdkuen, "Extraction and characterization of gelatin from chicken feet by acid and ultrasound-assisted extraction," Food Appl. Biosci. J., 2 (2014) 85-97.

[17] N. D. Mokhtar et al., "Extraction Optimization and Characterization of Collagen from Chicken (Gallus gallus domesticus) Feet," (2017) 79-85.

[18] E. Aykin-Dinçer, A. Koç, and M. Erbas, "Extraction and physicochemical characterization of broiler (Gallus gallus domesticus) skin gelatin compared to commercial bovine gelatin," Poult. Sci., 96 (2017) 4124-4131.

[19] L. Du, Z. Khiari, Z. Pietrasik, and M. Betti, "Physicochemical and functional properties of gelatins extracted from turkey and chicken heads," Poult. Sci., 92 (2013) 2463-2474.

[20] H. G. Reinhard Schrieber, Gelatine Handbook: Theory and Industrial Practice. London: John Wiley and Sons, (2007).

[21] N. Mhd Sarbon, F. Badii, and N. K. Howell, "Preparation and characterisation of chicken skin gelatin as an alternative to mammalian gelatin," Food Hydrocoll., 30 (2013) 143-151.

[22] H.-Y. Kim, K.-J. Kim, J.-W. Lee, G.-W. Kim, and C.-J. Kim, "Effects of Chicken Feet Gelatin and Wheat Fiber Levels on Quality Properties of Semi-dried Chicken Jerky,” Korean J. Food Sci. Anim. Resour., 32 (2012) 732 739.

[23] P. Nisha, R. S. Singhal, and A. B. Pandit, "Kinetic Modelling of Colour Degradation in Tomato Puree (Lycopersicon esculentum L.)," Food Bioprocess Technol., 4 (2011) 781-787.

[24] T. Liu et al., "Structure of Hyla rabbit skin gelatin as affected by microwave-assisted extraction," Int. J. Food Prop., 22 (2019) 1594-1607.

[25] M. Ahmad and S. Benjakul, "Characteristics of gelatin from the skin of unicorn leatherjacket (Aluterus monoceros) as influenced by acid pretreatment and extraction time," Food Hydrocoll., 25 (2011) 381-388.

[26] H. W. Kim et al., "Effects of soaking pH and extracting temperature on the physicochemical properties of chicken skin gelatin,” Korean J. Food Sci. Anim. Resour., 32 (2012) 316-322.

[27] M. Norziah, J. Nuraini, and K. Lee, "Studies on the extraction and characterization of fish oil from wastes of seafood processing industry," 2 (2009) 959 - 973.

[28] L. Lin, J. M. Regenstein, S. Lv, J. Lu, and S. Jiang, "An overview of gelatin derived from aquatic animals: Properties and modification,” Trends Food Sci. Technol., 68 (2017) 102-112. 
[29] A. P. Imeson, Thickening and Gelling Agents for Food. Springer, 1997.

[30] I. J. Haug, K. I. Draget, and O. Smidsrød, "Physical and rheological properties of fish gelatin compared to mammalian gelatin," 18 (2004) 203-213.

[31] K. Bakar, Jamilah, and Harvinder, "Properties of gelatins from skins of fish - Black tilapia (Oreochromis mossambicus) and red tilapia (Oreochromis nilotica)," Food Chem., 1 (2002) 81-84.

[32] S. H. Cho, M. L. Jahncke, K. B. Chin, and J. B. Eun, "The effect of processing conditions on the properties of gelatin from skate (Raja Kenojei) skins," Food Hydrocoll., 20 (2006) 810-816.

[33] A. Jongjareonrak, S. Benjakul, W. Visessanguan, and M. Tanaka, "Skin gelatin from bigeye snapper and brownstripe red snapper: Chemical compositions and effect of microbial transglutaminase on gel properties," Food Hydrocoll., 20 (2006) 1216-1222.

[34] G. P. Limited, S. Weaver, and F. Gels, “1 Introduction,”(1990) 233-289.

[35] M. Gudmundsson, "Rheological properties of fish gelatins," J. Food Sci., 67 (2002) 2172-2176. 